\title{
Estimation of the Impact of Large Regional Investment Projects on the Regional Development on the Example of Universiade-2013
}

\author{
Kramin M.V.a \\ Fatkhiev A.M. ${ }^{b}$ \\ Leonov V.A.c \\ Grigoryev R.A. ${ }^{d}$ \\ acd Institute of Economics, Management and Law, Kazan, Russian Federation, 420111 \\ ${ }^{b}$ Kazan Federal University, Institute of Management, Economics and Finance, Kazan, 420008, Russia
}

\section{Doi:10.5901/mjss.2015.v6n1s3p101}

\section{Abstract}

The work reveals and classifies the main socio-economic consequences of large international competitions. The impact of a large international sporting event on the socio-economic development of the host region is characterized with the institutional approach on the example of Universiade 2013 in Kazan. The impact of the Universiade on the socio-economic development in Tatarstan is estimated by economic sectors. In particular, the construction industry, hospitality industry, tourism, education in the Republic of Tatarstan are considered.

Keywords: region, large sporting event, the Universiade, socio-economic development, investment attraction, investment project, institutional approach

Large regional investment projects are distinguished by a variety of factors influencing them, and the consequences arising from them (Preuss, 2005; Spilling, 1996). One of the bright, diverse and significant projects by its impact on the regional development is the preparation for and hosting of the Summer Universiade 2013 in Kazan. This has become one of the key events of 2013. It has significantly raised the status of Kazan and has had a powerful impact on the socioeconomic development of the Republic of Tatarstan, as well as on Russia's economic system as a whole. The article is devoted to estimation of the impact of large regional investment projects on the socio-economic development of the region. The object of the evaluation of the results of the "Universiade-2013" project for Tatarstan Republic.

It is known from history that hosting of large international events, such as the Olympic Games, does not always have a significant and lasting impact on key socio-economic indicators like income, employment and inflation (Essex \& Chalkley, 1998). The positive long-term effect of the Universiade ${ }^{1}$ is possible in the case of the effective use of its heritage - tangible and intangible assets created within the framework of its preparation and conduct. In addition, it is necessary to take into account the economic situation, infrastructure and the status of the host region.

The impact of the Universiade on the regional economy is traditionally assessed out in two aspects: estimating the direct economic effect associated with income and expenses during the preparation and holding of the Universiade; evaluation of the long-term effect of the Universiade on the development of a city and region favorable image, on the increase of the investment attractiveness of the region² and, etc. (Hiller, 1998; Safiullin, Fatkhiev, \& Grigorian, 2014).

The positive socio-economic impact of the Universiade can be strengthened if this international project is consistent with the strategic plan of the city infrastructure and economy development (Roche, 1994).

In particular, in preparation for the summer Olympic Games of 2012 the London authorities invested 7.2 billion of \$ 9.9 billion pounds into roads and underground railway construction in East London. These transformations were necessary for the development of new business areas in that part of the city and enhanced the prestige of residential construction (Кузина \& Хамукова, 2009).

The budget of the Universiade in Kazan was about $\$ 4$ billion. They were used not only for the preparation and

1 Effects of hosting the Olympics in different countries (for example, Floros, 2010; Jasmand \& Maennig, 2008)

2 See also aspects of raising of investment attractiveness of the region (Safiullina, Ivanov, \& Beloborodova, 2014; Safiullina, Ivanov, \& Ramazanov, 2014; Safiullina, Odintsova, Zhilina, \& Shamsutdinova, 2014) 
hosting of the Games, but also for the city development. The USA (Atlanta) and Australia (Sydney) used relatively smaller budgets for the Summer Olympic Games - $\$ 1.8$ billion and $\$ 5$ billion respectively, due to the developed infrastructure in these cities.

In the emerging economies, where the hospitality industry, transport infrastructure and funds placement were poorly developed, the budgets of large sporting events were significant. For example, in Beijing the Olympic Games budget exceeded $\$ 36$ billion due to the low development of hotel infrastructure in Beijing. Two years before the Olympics 250 new hotels were opened in Beijing.

As was mentioned earlier, a large budget does not guarantee success and positive effect of hosting large sporting events $^{3}$. The examples of Montreal (Essex \& Chalkley, 1998; Kidd, 1992), Barcelona, Athens (Maloutas, Sayas, \& Souliotis, 2009) and London (Jennings, 2012) illustrate this assertion.

Montreal, which hosted the Olympic Games in 1976, suffered the greatest loss in the history of the Olympic Games. The losses occurred as a result of the excess of capital expenditures compared to initial estimates by $400 \%$. A large part of the loss was covered from the funds of the regional budget, but in Montreal was in debt after the Olympics.

The use of Olympic venues after the Games in Montreal has been difficult due to technical, organizational and logistical reasons. Thus, the Olympic Park, including the stadium, two swimming pools and a velodrome, was unusable after the Games, and the multi-storied Olympic Village, which housed the athletes during the Olympics, today is not used due to its remoteness from the Montreal business center.

The results of the Olympic Games in Barcelona is a striking example of the positive impact of the Games on infrastructure development and improvement of the tourism potential (the number of tourists visiting Barcelona has doubled in 2000 relative to 1991). Although the huge investments in infrastructure made by the Barcelona authorities significantly increased the burden on the city budget, which was then a deficit one, these expenses provided long-term economic growth and city development, by reducing the need of investments. Besides, the tourist sector growth positively influenced the income growth (Timiryasova \& Kramin, 2014).

A good example of a competent strategic planning of large sports events is London, which hosted the summer Olympic Games in 2012. Before the Games, London was a financial and tourist center, with a well-developed transport and service infrastructure, therefore, the main strategic objectives of the organizers were to maintain the high international status of the city and to maximize the economic effect from the Olympics. The concept of using the Olympic venues after the Olympic Games was formed. Special attention was paid to obtaining a synergistic effect of the application of the Olympics infrastructure (transport, engineering, service, shopping, tourist and business) in the city and surrounding areas development plans. For example, the "Stratford city", situated next to the Olympic Park, is a multipurpose venue including 150 thousand square meters of retail facilities, 500 square meters of offices, 4850 apartments, 2000 hotel rooms, a medical center and a school.

Some apartments were sold after being used as the Olympic Village. "Stratford city" has become the new business district of London in which it is planned to create about 30 thousand new jobs after the Olympics.

The project of the Olympic Games in London also includes technological innovations in the field of sustainable use of Olympic venues. The London Olympic stadium was constructed of inexpensive light structures. During the Olympic Games the London Olympic stadium could accommodate 80 thousand spectators. However, due to the lack of demand on such large-scale venue after the Olympics, it was partially dismantled, and the stadium capacity was reduced to 20 thousand people. The scenarios of using the stadium after the Olympics were designed beforehand. Due to the use of this technology, savings can exceed hundreds of millions of dollars for only one venue.

Below we view the issues of a sustainable long-term development of Kazan city and the Tatarstan Republic as a result of the preparation and hosting of the Summer Universiade in 2013. They are closely linked with all other activities of the Universiade organizers, as well as partner organizations and all stakeholders. During the development of postindustrial economy, the main accent of the research are made not at solely economic, but also institutional aspects.

We have studied the combination of all effects and changes caused by the Universiade, which have a substantial impact on the lives of future generations. These are the Games venues and infrastructure created for the competitions, socio-economic legacy in the form of new business opportunities, jobs and tourism, as well as a wide set "intangible" components of the legacy, including intellectual property, behavioral changes, and even changes of attitude.

The Universiade Strategic plan implies sustainable development of the city and the Republic after the Games. We interpret sustainable development as the process of change in which the exploitation of natural resources, direction of investments, orientation of scientific and technological development, personality development and institutional changes

${ }^{3}$ Possible socio-economic consequences of preparation, realization of sport events and subsequent use of facilities are discussed in various studies (see for example, Essex \& Chalkley, 2003, pp. 12-14; Ritchie, Shipway, \& Cleeve, 2009, pp. 145-147). 
are coordinated with each other and strengthen the current and future potential to meet human needs and aspirations (Зеркалов, 2012). Sustainable development implies satisfaction of the existing needs without limiting the ability of future generations (from the Report of the World Commission on Environment and Development at the session of the UN General Assembly on December 11, 1987). Sustainable development is one of the necessary conditions for maintaining high investment attraction of the region. The concept of sustainable development implies the following components:

- Economic (optimal use of limited resources and use of ecology-friendly technologies, including the extraction and processing of raw materials, creation of environmentally friendly products, minimization, recycling and disposal of waste)

- Social (focused on humans and aimed at preserving the stability of social and cultural systems, including the reduction in the number of destructive conflicts between people)

- Ecological (biological integrity and physical habitat preservation, keeping the abilities for self-restoration and dynamic adaptation of such systems to changes)

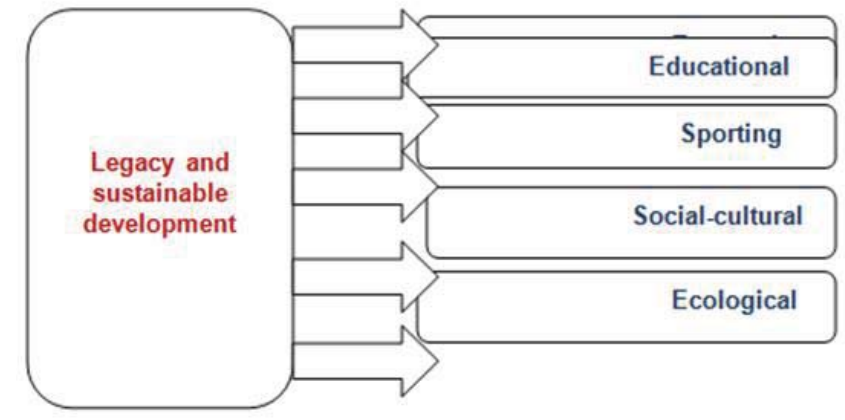

Fig. 1. Structural directions of the Universiade Legacy program and the sustainable development of the region after its implementation

For the institutional consolidation of the sustainable development concept, together with FISU on the example of "Kazan Universiade 2013" we developed and implemented a program of the World University Games Legacy, including impact indicators of the Games, introduced the principles of sustainable development within the organization of work of the Executive Directorate and at Universiade venues. The issues of the games legacy in the sphere of students' sports were viewed by A.G. Pasmurov before the Universiade (Пасмуров, 2011).

Let us consider the basic structural directions of the program of Universiade Legacy and sustainable development of the region as a result of its hosting (see Fig.1).

The key components of sporting tangible heritage of the Universiade 2013 are:

- modern and eco-efficient sports facilities intended for training professional athletes and development of mass sports in Russia

- upgrading of the existing infrastructure through the development and implementation of innovative sports technology in the interests of establishing a Federal center for summer sports

- the formation a new training base for the development of physical culture and sports, based on the latest achievements in the theory of physical education and sports training, pedagogy, psychology, biomechanics and biotechnology, medicine, informatics, nanotechnology and control.

The areas of cooperation between the Executive Committee and the Republican authorities in the preparation and maintenance of Games, that have had a significant impact on the socio-economic development of the Republic, are:

- Construction of the most modern facilities for training and competitions in accordance with the new standards in the field of eco-efficient construction;

- Development of regional transport infrastructure;

- Modernization of infrastructure of engineering networks and communications;

- Project of energy and water resources management;

- Projects in the field of waste management and wastewater treatment, including the modernization of existing waste management systems;

- Implementation of barrier-free environment programs;

- Educational and social projects. 
In order to maximize the positive effect of the Universiade 2013, one must consolidate the best ideas and efforts of all of the organizers and stakeholders, including representatives of community and non-governmental organizations, in order to integrate the principles of sustainable development and environmental protection into all the issues of preparation and hosting of the Universiade, which must earn the highest rating by participants, to leave a positive legacy for Kazan, Russia, and the University sports movement worldwide.

The main strategic goal is to achieve sustainable development and Universiade Legacy preservation in the following areas:

Thus, the Universiade 2013 had a powerful multilateral positive impact on the growth of investment potential of Kazan and Republic of Tatarstan. In this regard, a significant effect was and will be rendered by not only tangible, but also intangible factors. Among the latter one should note institutional factors, whose role in the development of economic systems is growing every year. Many investment risks of the Republic of Tatarstan will be reduced. Therefore, in general, the investment attractiveness and competitiveness of the Republic of Tatarstan in the international arena will increase. At the same time, the scale and character of this effect will largely depend on the efficiency of the Universiade legacy. From this point of view, the work has only just begun.

Our next task is to define the priority actions in this area and offer effective tools for their implementation. These will include tourism, hospitality, education, management innovations at the regional level, territorial marketing, corporate management institutions and integration mechanisms.

\section{References}

Essex, S., \& Chalkley, B. (1998). Olympic Games: catalyst of urban change. Leisure studies, 17(3), 187-206.

Essex, S., \& Chalkley, B. (2003). Urban transformation from hosting the Olympic Games. Barcelona: Centre d'Estudis Olímpics (UAB).

Floros, C. (2010). The impact of the Athens Olympic games on the Athens Stock Exchange. Journal of Economic Studies, 37(6), 647657.

Hiller, H. H. (1998). Assessing the impact of mega-events: a linkage model. Current issues in tourism, 1(1), 47-57.

Jasmand, S., \& Maennig, W. (2008). Regional income and employment effects of the 1972 Munich summer olympic games. Regional Studies, 42(7), 991-1002.

Jennings, W. (2012). Why costs overrun: risk, optimism and uncertainty in budgeting for the London 2012 Olympic Games. Construction Management and Economics, 30(6), 455-462.

Kidd, B. (1992). The culture wars of the Montreal Olympics. International Review for the Sociology of Sport, 27(2), 151-162.

Maloutas, T., Sayas, J., \& Souliotis, N. (2009). Intended and unintended consequences of the 2004 Olympic Games on the socio-spatial structure of Athens. Paper presented at the ISA-RC21 Sao Paulo conference. Inequality, inclusion and the sense of belonging.

Ovcharov, A. O., Fathiev, A. M. (2014). Statistical Analysis of Tourist Food Supply Industry. Mediterranean Journal of Social Sciences, 5(18), 269.

Preuss, H. (2005). The economic impact of visitors at major multi-sport events. European Sport Management Quarterly, 5(3), $281-301$.

Ritchie, B. W., Shipway, R., \& Cleeve, B. (2009). Resident perceptions of mega-sporting events: a non-host city perspective of the 2012 London Olympic Games. Journal of Sport \& Tourism, 14(2-3), 143-167.

Roche, M. (1994). Mega-events and urban policy. Annals of Tourism research, 21(1), 1-19.

Safiullin, L. N., Fatkhiev, A. M., \& Grigorian, K. A. (2014). The Triple Helix Model of Innovation. Mediterranean Journal of Social Sciences, 5(18), 203.

Safiullina, A. M., Odintsova, J. L., Zhilina, N. N., \& Shamsutdinova, M. R. (2014). The Main Participants of Innovation Climate Development (On the Example of the Russian Federation). Mediterranean Journal of Social Sciences, 5(18), 197. 